\title{
The occurrence of technological damage in slaughtered cattle, pigs, sheep and goats in the Czech Republic
}

\author{
Petra Doleželová ${ }^{1}$, Petra Mačáková ${ }^{1}$, Petr Chloupek ${ }^{1}$, Lenka Válková1, \\ Zbyněk Semerád ${ }^{2}$, Daniela Takáčová ${ }^{3}$
}

\begin{abstract}
${ }^{1}$ University of Veterinary Sciences Brno, Faculty of Veterinary Hygiene and Ecology, Department of Animal Protection and Welfare and Veterinary Public Health, Brno, Czech Republic

${ }^{2}$ State Veterinary Administration, Prague, Czech Republic

${ }^{3}$ University of Veterinary Medicine and Pharmacy in Košice, Department of Public Veterinary Medicine and Animal Welfare, Slovak Republic
\end{abstract}

Received September 22, 2021

Accepted November 9, 2021

\begin{abstract}
The occurrence of technological damage in cattle, pigs, sheep and goats reared and slaughtered in the Czech Republic was monitored by evaluation and analyzing results of post mortem inspections of official veterinarians from slaughterhouses in the period from 2010 to 2019. We found that technological damage was the most common in pigs, and less common in cattle, sheep and goats. Compared to other species, pigs have statistically the highest occurrence of lung congestion $(51.9 \%-19.3 \%$, in the order: sows, finishing pigs, piglets), insufficient technology processing $(0.200 \%-0.018 \%$, in the order: sows, finishing pigs, piglets), delayed evisceration $(0.04 \%-0.02 \%$, in the order: finishing pigs, sows, piglets $)$, muscle spoilage $(0.033 \%-0.004 \%$, in the order: piglets, finishing pigs, sows) and over-scalding $(0.028 \%-0.013 \%$, in the order: finishing pigs, piglets, sows). Compared to other species, cattle have statistically the highest incidence of different sensory deviations $(7.42 \%-0.33 \%$, in the order: calves, dairy cows, heifers, bulls) and insufficient bleeding (4.4\%-2.9\%, in the order: bulls, heifers, dairy cows, calves). In all monitored animal species, a similar level of the occurrence of contamination during the carcass processing was recorded $(0.37 \%-0.00 \%)$. In sheep and goats, technological damage is generally lower than in pigs and cattle.
\end{abstract}

Red meat carcass, slaughter, processing, defects

According to the Regulation (EU) No. 2017/625, carcasses and offal of all slaughtered animals are subject to post mortem inspection in the slaughterhouses to decide whether the meat is fit for human consumption. Further details for the performance of official controls can be found in the Commission Implementing Regulation (EU) No. 2019/627. The veterinary inspection in slaughterhouses ensures the safety and quality of meat, due to identification of patho-anatomical changes in the body and organs caused by a disease or poor pre-slaughter treatment of animals (Vecerek et al. 2020a; 2020b) but also due to changes caused by technological slaughterhouse procedures. Technological damage to the bodies and organs of animals caused by the slaughter technology and the subsequent processing of the whole bodies, parts of bodies, and organs of slaughtered animals is a problem that impairs the hygiene and related quality of meat and organs of slaughtered animals. The most important technological damage during the slaughter of cattle, pigs, sheep and goats is insufficient bleeding, lung congestion, delayed evisceration, overscalding, contamination during carcass processing, insufficient technological processing, spoilage of muscles and organs, and other sensory deviations.

Bleeding is used to kill an animal after simple stunning, when the two carotid arteries or the vessels from which they arise shall be systematically severed (Council Regulation (EC) No. 1099/2009). Both cattle and pigs are bled out with a thoracic stick aimed at severing

Address for correspondence:

MVDr. Petra Doleželová, Ph.D.

Department of Animal Protection and Welfare and Veterinary Public Health

Faculty of Veterinary Hygiene and Ecology

University of Veterinary Sciences Brno

Palackého tř. 1946/1, Brno 612 42, Czech Republic 
the brachiocephalic trunk which gives rise to the carotid arteries and vertebral artery supplying oxygenated blood to the brain. The bleeding efficiency at sticking is influenced by the blood vessels that are severed, the size and patency of the sticking wound, which is mostly dependent on appropriately skilled operators (Anil et al. 2000), the cardiac arrest at stunning, the orientation of the carcass - positioned horizontally or vertically, vasodilation or vasoconstriction in the capillary bed, tonic muscle contractions squeezing blood capillaries and vessels, and clonic activity causing movement of blood towards the sticking wound (Gregory 2005; EFSA 2020). Lung congestion occurs by aspirating fluid into the animal's respiratory tract when the animal is slaughtered. In pigs, when scalded in horizontal tanks, this aspirated fluid is usually scalding water (so-called scald water lungs), which manifests in the lungs as grey or grey-brown changes on the surface of the lungs (Nathues et al. 2008). Additionally, blood aspiration may occur during bleeding if the animal is insufficiently stunned (Gregory et al. 2009) or the trachea is accidentally ruptured during bleeding (EFSA 2004). Evisceration must be carried out without undue delay and in a manner that avoids contamination of the meat. In particular, measures must be taken to prevent the spillage of the digestive tract content during and after evisceration (Regulation (EC) No. 853/2004). Delayed evisceration occurs because of various failures on slaughter lines or processing disorders during the slaughter of animals (D'Souza et al. 1998), when due to the post mortem autolysis and multiplication of bacteria in the intestines of the slaughtered animal, gases such as methane, carbon dioxide, hydrogen, ammonia, hydrogen sulphide and mercaptans can be produced (Brooks 2016). Scalding is the process of treating pig carcasses with hot water or steam to loosen the bristles in the follicle to facilitate their removal. The scalding efficacy is determined by the timetemperature regime applied, as their inappropriate combination can lead to defects like over-scalding, which results from an unreasonably high temperature or an unreasonably long scalding time (Irshad and Arun 2013). The source of contamination of carcasses during the carcass processing are technological operations such as bleeding and evisceration of animals. In case the oesophagus is cut during sticking, the content of the rumen is regurgitated, and the edible meat in the neck area is visibly contaminated with digesta and can acquire a green stain (Alvseike et al. 2020). However, more important source of contamination is evisceration if the technological procedures are not obeyed and the gastrointestinal tract is cut through (Gill 2004). Visible contamination of carcasses results in bacterial contamination and reduced meat preservation. Muscle spoilage occurs in cases of insufficient or slow heat dissipation from the depths of the muscle, typically in cases of overfilled chilling rooms, insufficient air flow in the chilling rooms, and in cases of failures of slaughter lines, when the time from slaughter to evisceration increases (Pipek 2000). Muscle cells undergo natural autolytic processes, which in a suitable environment are combined with microbial proteolysis of meat, which lead to a typical sour-smelling odour and colour of the meat (Dave and Ghaly 2011). Insufficient technological processing usually involves errors in the dehairing of pigs; other sensory deviations include defects in colour, odour or consistency of meat.

Many studies have evaluated the carcass or organ condemnation from the pathological viewpoint, but a very limited number of studies focus specifically on the technological defects. Usually, these defects are included in the studies as other reasons for the condemnation or mechanical damage (Jibat et al. 2008; Klinger et al. 2021). However, also this technological damage, like other condemned organs or bodies in slaughterhouses, represents a significant economic loss (Fuseini 2012).

The aim of the study was to determine the overall occurrence of technological damage for a given species and category of animals in order to find out how often technological damage occurs for which species and possibly for which category of slaughtered animals. Furthermore, the occurrence of individual technological damage was compared between 
individual species and categories of slaughtered cattle, pigs, sheep and goats in order to find out in which species and categories they occur most commonly.

\section{Materials and Methods}

We evaluated the occurrence of technological damage detected during veterinary post mortem inspection in cattle, pigs, sheep and goats reared and slaughtered in the Czech Republic in the period from 2010 to 2019. The occurrence of technological damage in the monitored period was recorded by official veterinarians after slaughter in all slaughterhouses located in the Czech Republic as a part of the result of post mortem veterinary inspection. In total, technological damage was monitored in 1136754 dairy cows, 257912 heifers, 1015541 bulls, 104459 calves, 586245 sows, 25027303 fattening pigs, 123191 piglets, 22815 sheep, 114264 lambs, 1348 goats, 5778 kids. The following technological damage was recorded: insufficient bleeding, congestion of the lungs, delayed evisceration, over-scalding, contamination during carcass processing, insufficient technological processing, spoilage of muscles and organs, and other sensory deviations. The assessment and records of technological damage in slaughtered animals was carried out by official veterinarians of the State Veterinary Administration, who classified technological damage on the basis of their appearance according to the knowledge acquired through their study and training.

The obtained data were classified according to the individual species and categories of animals, and for each monitored species and category of animals, the numbers of the individual technological damage in the individual years from 2010 to 2019 were recorded. The ratio of the occurrence of technological damage to the number of performed observations (number of slaughtered animals $\times$ number of types of technological damage) expressed in $\%$ for the whole monitored period of 10 years was calculated and the total number of technological damages was graphically represented for each species and category of slaughtered animals. To avoid meaningless results when the number of findings exceeds the number of animals slaughtered, the total technological damage ratio was calculated to the number of performed observations (i.e. number of slaughtered animals $\times$ number of types of technological damage) and not to the number of slaughtered animals. Thus, the resulting total technological damage is analogous to the resulting individual technological damage. Furthermore, the occurrence of individual technological damage for the entire monitored period was compared among the individual species and categories of slaughtered cattle, pigs, sheep and goats in order to determine in which species and category of slaughtered animals the relevant technological damage occurs most often, i.e. that the slaughter and subsequent processing of the carcass and organs of slaughtered animals is not technologically resolved at a level corresponding to other species and categories of animals with a lower incidence of damage, and in which species and categories of slaughtered animals the relevant technological damage occurs least frequently, i.e. slaughter and subsequent processing of the carcass and organs of slaughtered animals is technologically solved better compared to other species and categories of animals. The share of the occurrence of individual technological damage to the number of slaughtered animals was calculated, expressed in \% for the entire monitored period of 10 years, and the amount of damage for all species and categories of slaughtered animals was graphically represented for each type of technological damage.

The results were statistically evaluated using the program Unistat 6.5 for Excel (Unistat Ltd., London, UK). To determine the significance of differences in the occurrence of relevant technological damage between species and categories of slaughtered animals, the differences were tested by the Chi-square test using a $2 \times 2$ contingency table with the calculation of the significance of the difference for $P \leq 0.05$.

\section{Results}

The occurrence of technological damage in cattle, pigs, sheep and goats slaughtered over the entire monitored period of 10 years between 2010 and 2019 is shown in Table 1 and the comparison of the occurrence of technological damage in total between the individual categories of slaughtered cattle, pigs, sheep and goats is shown in Fig. 1.

The results show that the highest occurrence of technological damage was detected in pigs $(6.86 \%-2.62 \%$, in the order: sows, fattening pigs, piglets), followed by cattle $(1.73 \%-1.39 \%$, in the order: calves, bulls, dairy cows, heifers $)$, sheep $(1.55 \%-1.00 \%$, in the order: sheep, lambs) and goats $(1.51 \%-0.93 \%$, in the order: goats, kids). A statistical comparison of the occurrence of technological damage in individual categories revealed a highly significant difference between almost all categories, except for goats vs. dairy cows $(P=0.47)$, goats vs. heifers $(P=0.29)$, goats vs. bulls $(P=0.33)$, goats vs. calves $(P=0.08)$, goats vs. sheep $(P=0.73)$ and also kids vs. lambs $(P=0.13)$.

The comparison of the occurrence of insufficient bleeding between individual categories of cattle, pigs, sheep and goats slaughtered within the period of 2010-2019 is shown in Fig. 2. 


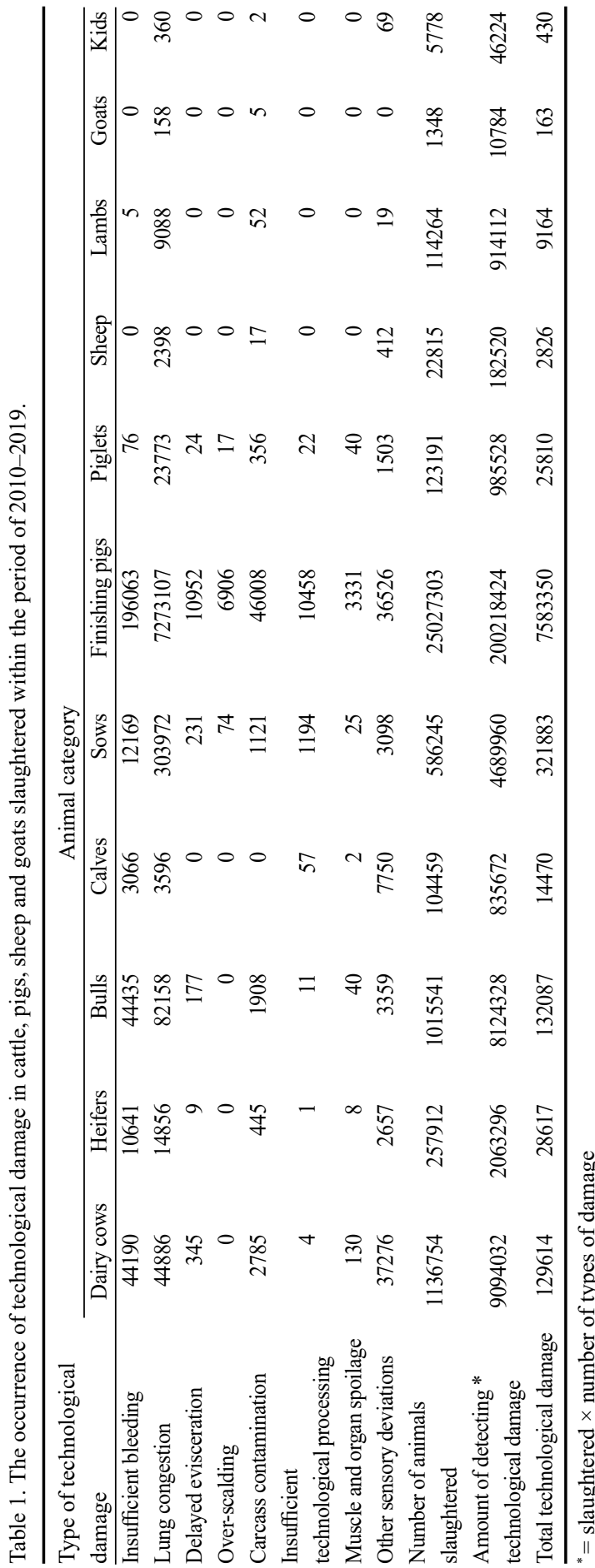

The results show that the highest occurrence of insufficient bleeding was recorded in cattle $(4.4 \%-2.9 \%$, in the order: bulls, heifers, dairy cows, calves), followed by pigs $(2.1 \%-0.06 \%$, in the order: sows, finishing pigs, piglets) and in sheep and goats it was recorded rarely or not at all. The statistical comparison of the occurrence of insufficient bleeding in individual categories revealed a highly significant difference among almost all categories, except for goats vs. piglets $(P=0.36)$, goats vs. sheep $(P=1.00)$, goats vs. lambs $(P=0.81)$, kids vs. piglets $(P=0.06)$, kids vs. sheep $(P=1.00)$, kids vs. lambs $(P=0.62)$ and kids vs. goats $(P=1.00)$.

The comparison of the occurrence of lung congestion between individual categories of cattle, pigs, sheep and goats slaughtered within the period of 2010-2019 is shown in Fig. 3.

From the results it is obvious that the highest incidence of lung congestion was found in pigs $(51.9 \%-19.3 \%$, in the order: sows, finishing pigs, piglets), followed by goats $(11.7 \%-6.2 \%$, in the order: goats, kids) and sheep $(10.5 \%-8.0 \%$, in the order: sheep, lambs) and the lowest incidence was in cattle $(8.1 \%-3.4 \%$, in the order: bulls, heifers, dairy cows, calves). A statistical comparison of the occurrence of lung congestion in individual categories revealed a highly significant difference between almost all categories, except for lambs vs. bulls $(P=0.11)$, goats vs. sheep $(P=0.17)$ and kids vs. heifers $(P=0.14)$.

The comparison of the occurrence of delayed evisceration between individual categories of cattle, pigs, sheep and goats slaughtered within the period of 2010-2019 is shown in Fig. 4. 


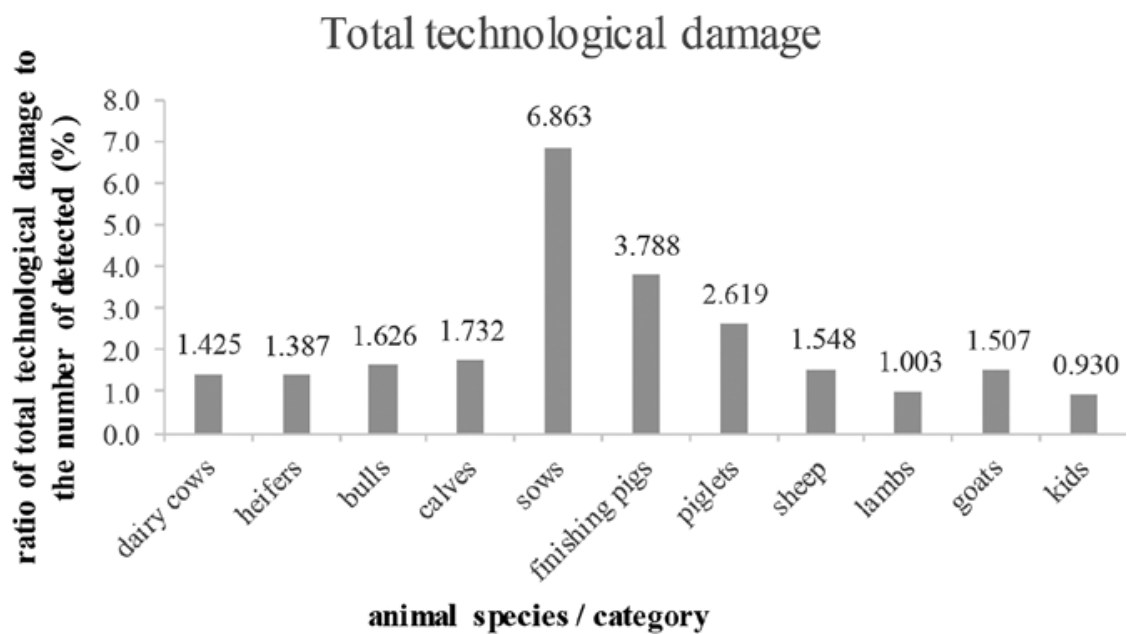

Fig. 1. Comparison of the occurrence of total technological damage between individual categories of cattle, pigs, sheep and goats slaughtered within the period of 2010-2019.

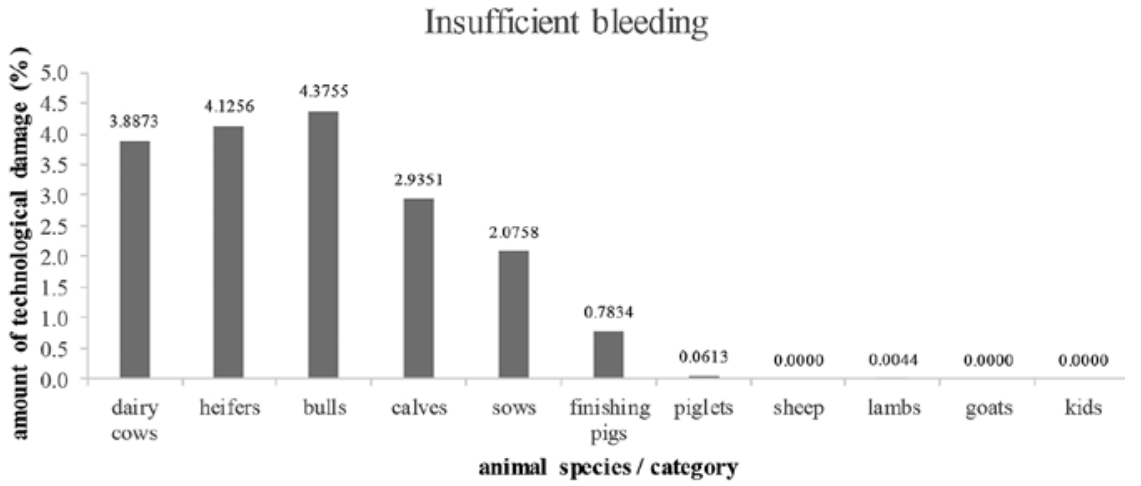

Fig. 2. Comparison of the occurrence of insufficient bleeding between individual categories of cattle, pigs, sheep and goats slaughtered within the period of 2010-2019.

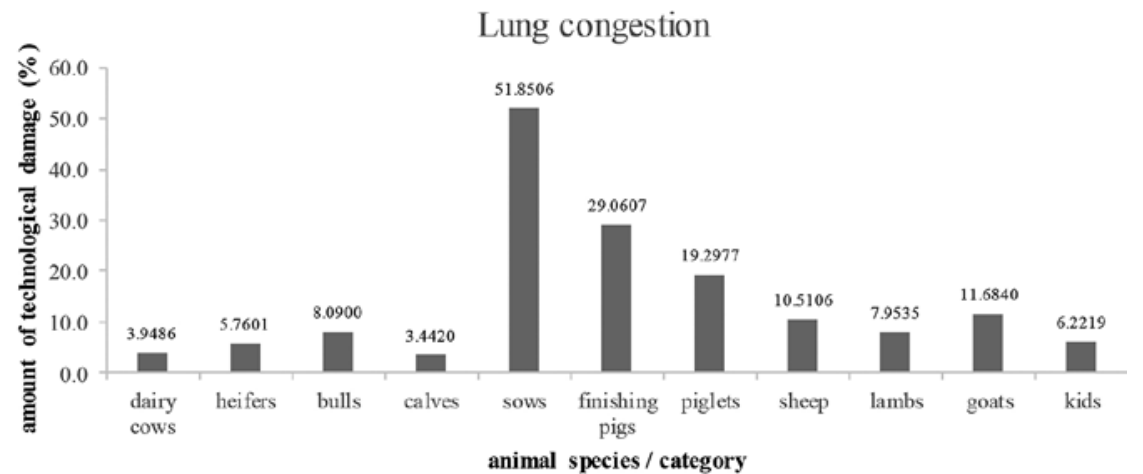

Fig. 3. The comparison of the occurrence of lung congestion between individual categories of cattle, pigs, sheep and goats slaughtered within the period of 2010-2019. 
It shows that the highest occurrence of delayed evisceration was reported in pigs $(0.04 \%-0.02 \%$, in the order: finishing pigs, sows, piglets $)$, followed by cattle $(0.03 \%-0.0 \%$, in the order: dairy cows, bulls, heifers, calves); in sheep and goats no occurrence was reported. By statistical comparison of the occurrence of delayed evisceration in the individual categories, a highly significant difference was revealed between almost all categories, in which this damage occurred, except for the comparison of calves vs. heifers $(P=0.06)$, finishing pigs vs. sows $(P=0.11)$, and piglets vs. bulls $(P=0.61)$.

The comparison of the occurrence of over-scalding between individual categories of cattle, pigs, sheep and goats slaughtered within the period of 2010-2019 is shown in Fig. 5.

As shown, over-scalding occurred only in pigs $(0.028 \%-0.013 \%$, in the order: finishing pigs, piglets, sows), whereas a significant difference was found in the categories of sows vs. finishing pigs and finishing pigs vs. piglets. In cattle, sheep, and goats the scalding technology is not used, therefore, no over-scalding could be detected.

The comparison of the occurrence of carcass contamination between individual categories of cattle, pigs, sheep and goats slaughtered within the period of 2010-2019 is shown in Fig. 6.

The results shown indicate that the highest occurrence of carcass contamination was detected in pigs $(0.29 \%-0.18 \%$, in the order: piglets, sows, finishing pigs), in cattle $(0.25 \%-0.00 \%$, in the order: dairy cows, bulls, heifers, calves $)$ and goats $(0.37 \%-0.03 \%$, in the order: goats, kids); the lowest occurrence was detected in sheep $(0.07 \%-0.05 \%$, in the order: sheep, lambs). The statistical comparison of the occurrence of carcass contamination in the individual categories revealed a highly significant difference between almost all categories, except for the comparison of goats vs. dairy cows $(P=0.35)$, goats vs. heifers $(P=0.08)$, goats vs. bulls $(P=0.12)$, goats vs. sows $(P=0.13)$, goats vs. finishing pigs $(P=0.11)$, and goats vs. piglets $(P=0.58)$, then bulls vs. heifers $(P=0.11)$, sows vs. heifers $(P=0.07)$, sows vs. bulls $(P=0.63)$, finishing pigs vs. heifers $(P=0.18)$, finishing pigs vs. bulls $(P=0.36)$, finishing pigs vs. sows $(P=0.19)$, lambs vs. sheep $(P=0.10)$, and also kids vs. lambs $(P=0.49)$ and kids vs. sheep $(P=0.21)$.

The comparison of the occurrence of insufficient technological processing between individual categories of cattle, pigs, sheep and goats slaughtered within the period of 2010-2019 is shown in Fig. 7.

From the figure it is clear that the highest occurrence of insufficient technological processing was recorded in pigs $(0.200 \%-0.018 \%$, in the order: sows, finishing pigs, piglets), followed by cattle $(0.054 \%-0.0003 \%$, in the order: calves, bulls, heifers, dairy cows); in sheep and goats insufficient technological processing was not detected. A statistical comparison of the occurrence of insufficient technological processing in individual categories revealed a highly significant difference between almost all categories, except for the comparison of heifers vs. dairy cows $(P=0.84)$, bulls vs. heifers $(P=0.30)$ and finishing pigs vs. calves $(P=0.05)$.

The comparison of the occurrence of muscle or organ spoilage between individual categories of cattle, pigs, sheep and goats slaughtered in slaughterhouses in the period of 2010-2019 is shown in Fig. 8.

The results show that the highest occurrence of muscle and organ spoilage was found in pigs $(0.033 \%-0.004 \%$, in the order: piglets, finishing pigs, sows $)$, followed by cattle $(0.011 \%-0.002 \%$, in the order: dairy cows, bulls, heifers, calves), in sheep and goats the spoilage of muscle and organs was not recorded. In the statistical comparison of the occurrence of muscle or organ spoilage in individual categories of slaughtered animals, no difference was found between the categories of dairy cows vs. finishing pigs $(P=0.08)$, heifers vs. bulls; calves and sows $(P=0.56 ; 0.54$ a 0.46$)$, bulls vs. calves and bulls vs. sows $(P=0.32,0.78$ resp. $)$ and also calves vs. sows $(P=0.28)$. 


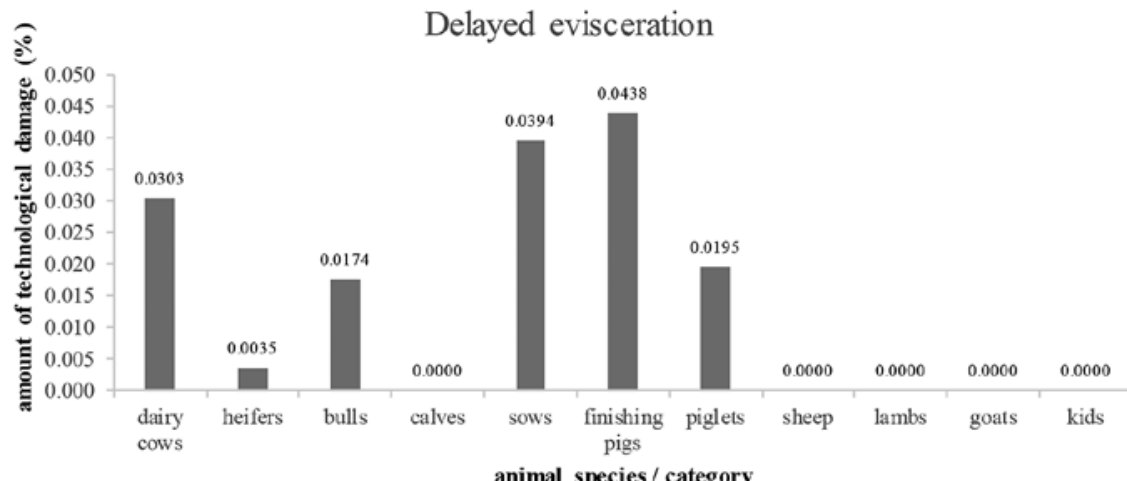

Fig. 4. The comparison of the occurrence of delayed evisceration between individual categories of cattle, pigs, sheep and goats slaughtered within the period of 2010-2019.

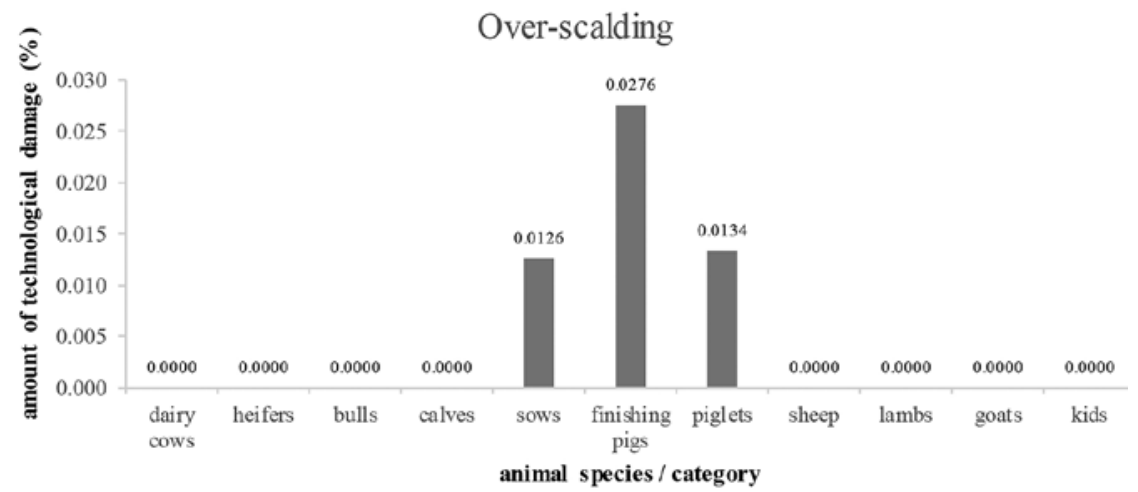

Fig. 5. The comparison of the occurrence of over-scalding between individual categories of cattle, pigs, sheep and goats slaughtered within the period of 2010-2019.

\section{Carcass contamination}

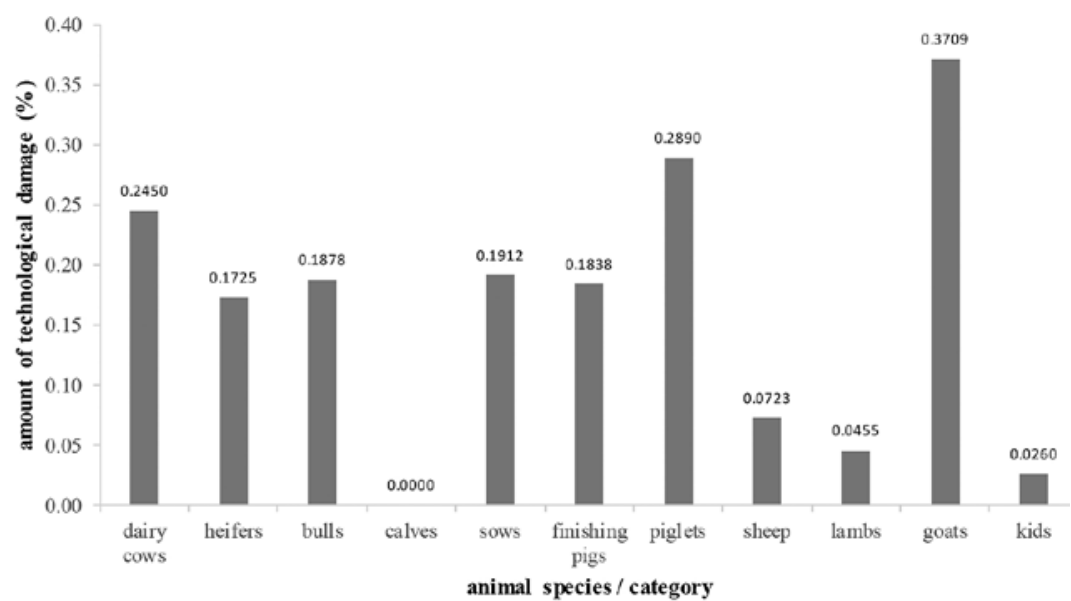

Fig. 6. Comparison of the occurrence of carcass contamination between individual categories of cattle, pigs, sheep and goats slaughtered within the period of 2010-2019. 


\section{Insufficient technological processing}

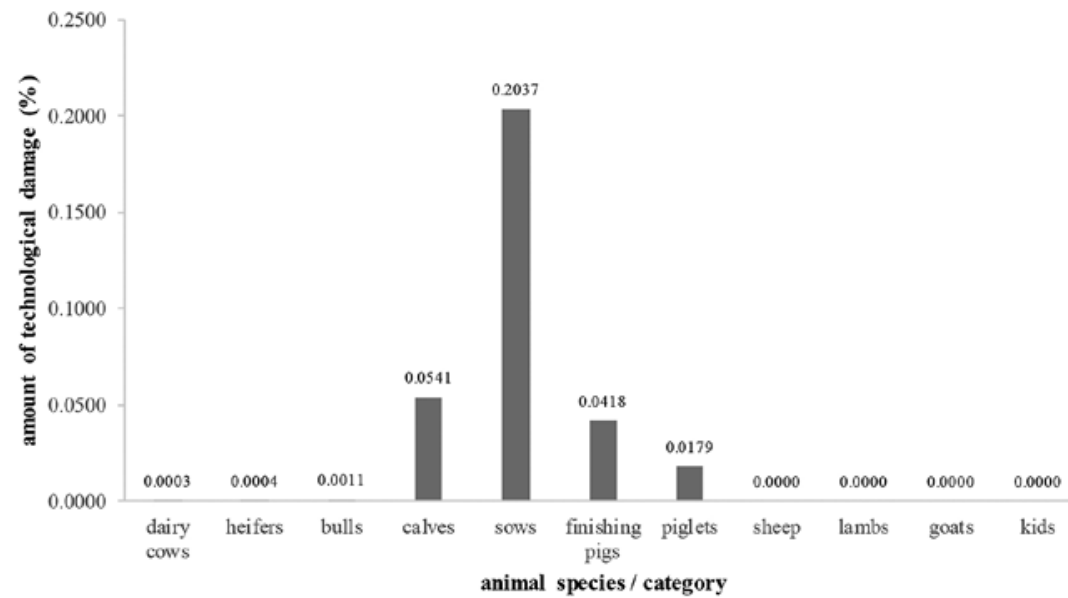

Fig. 7. Comparison of the occurrence of insufficient technological processing between individual categories of cattle, pigs, sheep and goats slaughtered within the period of 2010-2019.

Muscle and organ spoilage

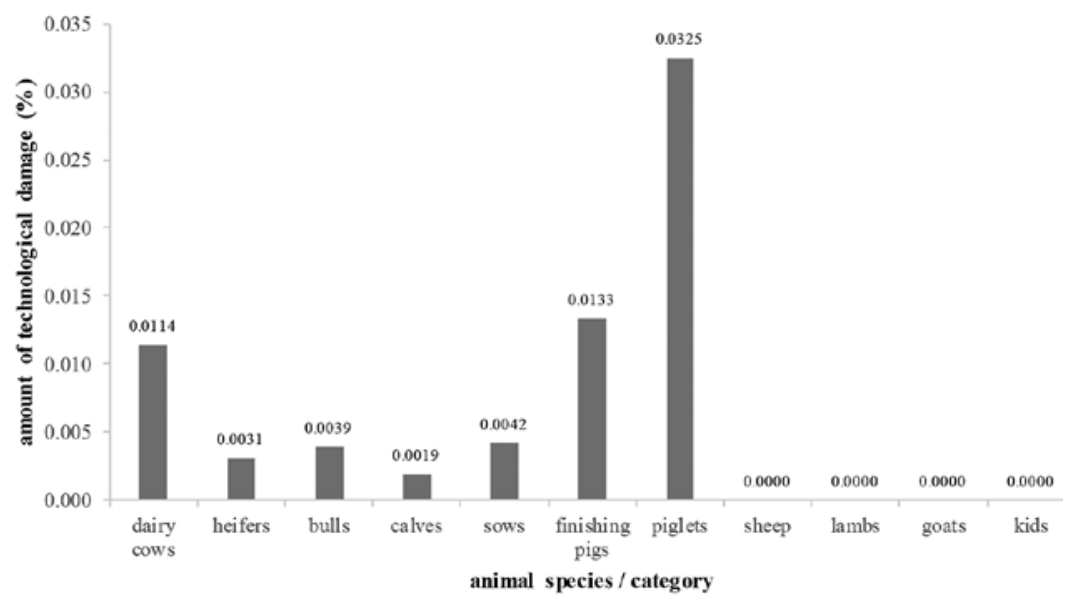

Fig. 8. Comparison of the occurrence of muscle or organ spoilage between individual categories of cattle, pigs, sheep and goats slaughtered within the period of 2010-2019.

The comparison of the occurrence of other sensory deviations between individual categories of cattle, pigs, sheep and goats slaughtered within the period of 2010-2019 is shown in Fig. 9.

The results indicate that the highest occurrence of other sensory deviations was detected in cattle $(7.42 \%-0.33 \%$, in the order: calves, dairy cows, heifers, bulls), followed by sheep $(1.80 \%-0.02 \%$, in the order: sheep, lambs), goats $(1.19 \%-0.00 \%$, in the order: kids, goats) and the lowest occurrence was detected in pigs $(1.22 \%-0.15 \%$, in the order: piglets, sows, finishing pigs). The statistical comparison of the occurrence of other sensory deviations in individual categories revealed a highly significant difference between almost all categories, except for the comparison of kids vs. heifers $(P=0.22)$, kids vs. piglets $(P=0.86)$, goats vs. finishing pigs $(P=0.16)$, and goats vs. lambs $(P=0.64)$. 


\section{Other sensory deviations}

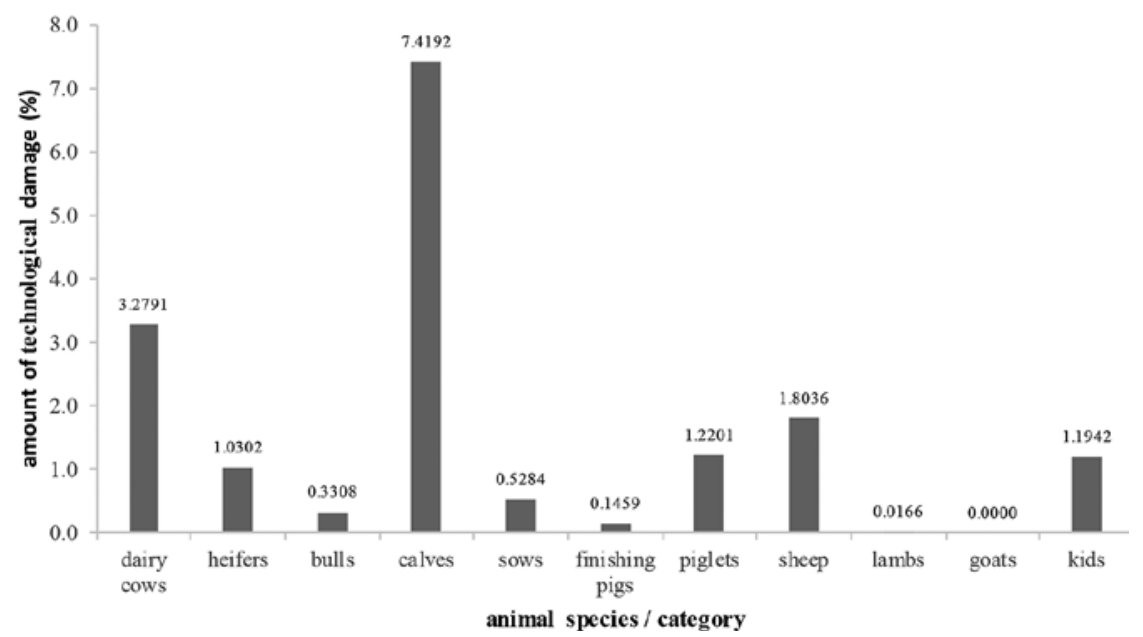

Fig. 9. Comparison of the occurrence of other sensory deviations between individual categories of cattle, pigs, sheep and goats slaughtered within the period of 2010-2019.

\section{Discussion}

The level of the occurrence of total technological damage and the level of the occurrence of individual technological damage in the slaughter of cattle, pigs, sheep and goats are indicators of the suitability of the technology and procedures for slaughtering individual species and categories of animals and their subsequent processing. We have found out that the highest occurrence of total technological damage was detected in pigs $(6.9 \%$ in sows, $3.8 \%$ in finishing pigs and $2.6 \%$ in piglets), followed by cattle, and the lowest occurrence was found in sheep and goats. The reason for such results might be in the number of animals slaughtered and processed in the slaughterhouse per unit of time, as the rate of slaughter and processing of pigs is significantly higher (up to 1500 pigs per shift, Pipek 2000) and the consideration of possible technological damage is lower than in cattle (250 cattle per shift, Pipek 2000). Also, the procedures of bleeding and subsequent processing of slaughtered animals in pigs differ from cattle, leading to a significantly higher incidence of technological damage at the level of lung congestion, delayed evisceration, muscle spoilage and, in a specific procedure, over-scalding in pigs compared to cattle. This creates conditions for a higher incidence of individual technological damage in pigs compared to cattle. Contrary to our study, other authors did not focus in their findings specifically on technological defects in slaughterhouses. Therefore, the results of their studies may vary depending on the methodology they used. Klinger et al. (2021) determined the prevalence of $2.9 \%$ for slaughter technique-induced abnormalities in pigs, however, it represents the prevalence for the total pathological findings. Similarly, Fus eini (2012) identified contamination as one of the causes for cattle carcass condemnation, which represented the prevalence of $12.22 \%$ of the total findings recorded. We must also take into account the accuracy of the routine meat inspection, as there is probably certain variability in the post mortem findings that can be attributed to the official inspectors (Schleicher et al. 2013). Comparing the individual technological damages, we have found that the most frequent technological damage is lung congestion in pigs and insufficient bleeding in cattle. Obviously, the highest occurrence of lung congestion in pigs is given by the slaughtering 
procedure, where scalding is used for the treatment of the carcass surface. When horizontal scalding tanks are used, the scalding water is very often aspirated into the pigs' lungs. Similarly, this damage was reported in Austria where slaughterhouses are smaller and the lungs do not play an important role in the marketing of meat, therefore, horizontal scalding tanks are still used (Klinger et al. 2021). However, as Schleicher et al. (2013) pointed out, the problem may be the system of monitoring this damage, which can be confused with other lesions on the lungs. Lung congestion with blood may occur in cases when the trachea is cut accidentally or purposely, e.g. in sheep and goats, when the bleeding cut is performed as the neck cut, causing damage to the trachea and esophagus, and consequently blood or the contents of the digestive tract may be aspirated into the lungs (EFSA 2004). A possible explanation for the occurrence of insufficient bleeding in cattle could be in the size of the bled animal, as in cattle with a large body volume even a minor mistake in performing the bleeding cut will more often cause insufficient bleeding than in the smaller body of pigs. The most often used procedure for bleeding is the thoracic stick, which must affect the brachiocephalic trunk, which requires a skilled person and a sufficiently long knife blade. According to Troeger and Meiler (2007), the bleed-out efficiency was improved when the bleeding procedure was performed by a skilled person compared to an unskilled operator (4.3 vs. $4.1 \%$ carcass weight loss). Also, Anil et al. (2000) determined that the brachiocephalic trunk was missed by the sticking knife in $43 \%$ and $47 \%$ of cases following long (11.2 cm on average) and short ( $4.5 \mathrm{~cm}$ on average) sticking attempts, respectively. Moreover, the of blood loss rate was significantly reduced when the sticking wound was short. In addition, cattle have a problem with the possible occurrence of so-called carotid occlusion (ballooning), if bleeding occurs mainly through the neck cut, which can lead to the retraction of the artery into the surrounding connective tissue (so-called false aneurysm), its swelling and accumulation of blood at the site of the retraction resulting in disruption of bleeding (Gregory et al. 2006). The same authors showed that ballooning is rather frequent in cattle and calves (in one artery it was present in $16 \%$ of cattle and $25 \%$ of calves), but it was absent in sheep. In cases of delayed evisceration, which according to our results mainly occurred in pigs, D' Souza et al. (1998) state that the most common causes of delays in the processing of pig carcasses in Australian slaughterhouses are due to manual manipulations with the carcass at evisceration or failures of the processing lines. The legislation sets that evisceration shall be carried out without undue delay (Regulation 853/2004), but the exact time is not established. Maynard and Warner (1996) recommended the time of $20 \mathrm{~min}$ from stunning to evisceration to prevent a rapid decline of $\mathrm{pH}$ in the meat. The specificity of the technological processing of pig carcasses is the reason for occurrence of the overscalding damage in pigs, because scalding (and subsequent dehairing) applies exclusively to pigs and therefore this technological damage cannot be found in cattle, sheep, or goats. Effective scalding needs an optimal combination of temperature and time (Irshad and Arun 2013). Mowafy and Cassens (1975) found that the use of a scalding temperature higher than $58{ }^{\circ} \mathrm{C}$ for more than 6 min has detrimental effects on the quality of the skin, marking it as over-scalded.

The main cause of the carcass contamination is attributed to improper evisceration of the animals. In case the digestive tract is cut, its content can spill into the surrounding tissues and contaminate either the meat or other organs (Gill 2004). It is clear from the results that contamination during the processing occurs in cattle, pigs, and goats, being lower only in sheep. Fuseini (2012) detected contamination of cattle carcasses in $13.53 \%$ of slaughtered animals. Also Jaja et al. (2018) identified improper evisceration as one of the major causes of offal and carcass condemnation. In the category of insufficient technological processing, deficiencies in dehairing are included in pigs, i.e., the technological damage related exclusively to pigs, therefore the incidence of this technological damage is high in pigs when comparing the species and categories of slaughtered animals. The occurrence of 
technological damage muscle and organ spoilage is connected to the technology of boning carcasses and subsequent cooling of halves and/or quarters of animals. Pigs are distributed for further processing in halves and due to the speed of the technology moving the two halves on the slaughterhouse line, they may remain stuck together and create an environment for spoilage and/or insufficient cooling with subsequent spoilage of the meat. For similar reasons, conditions for spoilage of meat may be created for cattle that are distributed for further processing in quarters. Technological damage assigned as other sensory deviations has different causes that can be divided into two groups - slaughtering technology/ processing of carcasses and intravital changes connected to animal health. Technological causes include bruises caused by pre-slaughter handling and lairage of animals at slaughter. Romero et al. (2013) identified longer lairage time at slaughter as a risk factor for the bruising of cattle, since the lairage time of 18 to $24 \mathrm{~h}$ at the plant increased the prevalence of bruises 2.1 times compared to lairage periods of between 12 and $18 \mathrm{~h}$. For pigs, also the longer resting time, mixing of unfamiliar groups of pigs, and inappropriate design of the facilities were identified as major causes of bruising (Faucitano 2001). Intravital causes include local inflammatory changes, swelling, icteric discoloration, adhesions, scars and other changes in the shape, consistency or colour. The variety of causes leading to other sensory abnormalities is because this defect has been detected in all species and categories of slaughtered animals. The most common occurrence was found in cattle (Valkova et al. 2021) which corresponds to a higher incidence of intravital changes in cattle (mostly in dairy cows in the sense of older animals and calves in terms of their culling for lower health and fitness). In sheep, higher incidence of these lesions corresponds to similar causes as in dairy cows. Interestingly, a higher incidence of this technology damage was found in kids, which could correspond to the constitution and body surface of kids, where haematomas, swelling, and damage to the limbs may occur more easily when handled in slaughterhouses.

Differences in the level of the occurrence of individual technological damage in slaughtered species and categories of animals indicate the need to target veterinary supervision for a higher number of damage occurrences and, conversely, for a low number of individual technological damage occurrences, to allow the transfer of veterinary supervision capacities from the control of such damage to the place of control of technological damage with a significantly higher incidence. The frequency of technological damage indicates the level of managing the technology of slaughtering and subsequent processing of carcasses and organs of slaughter animals and varies according to the species and categories of slaughtered animals. Therefore, the level of the occurrence of individual types of technological damage indicates specific problems in managing the technology of slaughtering and post-processing in different species and categories of slaughtered animals.

In conclusion, we found that technological damage is the most common in pigs, and less frequent in cattle, sheep, and goats. Compared to other species, pigs have statistically the highest occurrence of lung congestion $(51.9 \%-9.3 \%$, in the order: sows, finishing pigs, piglets), insufficient technology processing (particularly insufficient dehairing) $(0.200 \%-0.018 \%$, in the order: sows, finishing pigs, piglets), delayed evisceration $(0.04 \%-0.02 \%$, in the order: finishing pigs, sows, piglets), muscle spoilage $(0.033 \%-0.004 \%$, in the order: piglets, finishing pigs, sows) and over-scalding $(0.028 \%-0.013 \%$, in the order: finishing pigs, piglets, sows). Compared to other species, cattle have statistically the most occurred different sensory deviations $(7.42 \%-0.33 \%$, in the order: calves, dairy cows, heifers, bulls) and insufficient bleeding $(4.4 \%-2.9 \%$, in the order: bulls, heifers, dairy cows, calves). In all monitored animal species, a similar level of the occurrence of contamination during carcass processing $(0.37 \%-0.00 \%)$ was recorded. In sheep and goats, the technological damage is generally lower than the technological damage in pigs and cattle. 


\section{Acknowledgements}

This work was supported by the Veterinary Scientific Committee, Veterinary Research Institute and Ministry of Agriculture of the Czech Republic (project title: Technological damage and their occurrence in slaughtered animals, 2021)

\section{References}

Alvseike O, Prieto M, Bjørnstad PH, Mason A 2020: Intact gastro-intestinal tract removal from pig carcasses in a novel Meat Factory Cell approach. Acta Vet Scand 62: 1-5

Anil MH, Whittington PE, McKinstry JL 2000: The effect of the sticking method on the welfare of slaughter pigs. Meat Sci 55: 315-319

Brooks JW 2016: Postmortem changes in animal carcasses and estimation of the postmortem interval. Vet Pathol 53: 929-940

Commission Implementing Regulation (EU) 2019/627 of 15 March 2019 laying down uniform practical arrangements for the performance of official controls on products of animal origin intended for human consumption in accordance with Regulation (EU) 2017/625 of the European Parliament and of the Council and amending Commission Regulation (EC) No 2074/2005 as regards official controls. In: EUR-lex. Available at: https://eur-lex.europa.eu/. Accessed September 15, 2021

Council Regulation (EC) No 1099/2009 of 24 September 2009 on the protection of animals at the time of killing. In: EUR-lex. Available at: https://eur-lex.europa.eu/. Accessed September 15, 2021.

Dave D, Ghaly AE 2011: Meat spoilage mechanisms and preservation techniques: A critical review. Am J Agric Biol Sci 6: 486-510

EFSA 2004: Opinion of the Scientific Panel on Animal Health and Welfare (AHAW) on a request from the Commission related to welfare aspects of the main systems of stunning and killing the main commercial species of animals. EFSA Journal 2: 45

EFSA AHAW Panel (EFSA Panel on Animal Health and Welfare), Nielsen SS, Alvarez J, Bicout DJ, Calistri P, Depner K, Drewe JA, Garin-Bastuji B, Gonzales Rojas JL, Gortazar Schmidt C, Michel V, Miranda Chueca MA, Roberts HC, Sihvonen LH, Spoolder H, Stahl K, Velarde A, Viltrop A, Candiani D, Van der Stede Y, Winckler C 2020: Scientific Opinion on the welfare of cattle at slaughter. EFSA Journal 18: 6275

Faucitano L 2001: Causes of skin damage to pig carcasses. Can J Anim Sci 81: 39-45

Fuseini A 2012: A survey of post mortem meat inspection data collected in a beef abattoir in South Wales. Dissertation thesis, University of Bristol.

Gill CO 2004: Visible contamination on animals and carcasses and the microbiological condition of meat. J Food Prot 67: 413-419

Gregory NG 2005: Recent concerns about stunning and slaughter. Meat Sci 70: 481-491

Gregory NG, Shaw FD, Whitford JC, Patterson-Kane JC 2006: Prevalence of ballooning of the severed carotid arteries at slaughter in cattle, calves and sheep. Meat Sci 74: 655-657

Gregory NG, von Wenzlawowicz M, von Holleben K 2009: Blood in the respiratory tract during slaughter with and without stunning in cattle. Meat Sci 82: 13-16

Irshad A, Arun T 2013: Scalding and its significance in livestock slaughter and wholesome meat production. Int J Livest Res 3: 45-53

Jaja IF, Mushonga B, Green E, Muchenje V 2018: Factors responsible for the post-slaughter loss of carcass and offal's in abattoirs in South Africa. Acta Trop 178: 303-310

Jibat BT, Ejeta G, Asfaw Y, Wudie A 2008: Causes of abattoir condemnation in apparently healthy slaughtered sheep and goats at HELMEX abattoir, Debre Zeit, Ethiopia. Rev Med Vet 159: 305-311

Klinger J, Conrady B, Mikula M, Käsbohrer A 2021: Agricultural holdings and slaughterhouses' impact on patterns of pathological findings observed during post-mortem meat inspection. Animals 11: 1442

Maynard P, Warner RD 1996. National Pork quality improvement program, DAV 119P, Annual Report, Pig Research and Development Corporation, Australia.

Mowafy M, Cassens RG 1975: Comparative study on different scalding methods and their effect on the quality of pig skin. J Anim Sci 41: 1291-1297

Nathues H, Hewicker-Trautwein M, Grosse Beilage E 2008: Differenzierung schlachtungsbedingeter Artefakte von pneumonischen Veränderungen beim Lungencheck an Schlachtschweinen (in German, Differentiation between pneumonic lung lesions and technical artefacts during scoring of lungs from pigs at the abattoir). Tierärztliche Praxis Grosstiere 4: 258-262

Pipek P 2000: Porážení jatečných zvířat. In: Steinhauser L (Ed.): Produkce masa. Last, Tišnov, pp. 277-304

Regulation (EC) no 853/2004 of the European parliament and of the council of 29 April 2004 laying down specific hygiene rules for on the hygiene of foodstuffs. In: EUR-lex. Available at: https://eur-lex.europa.eu/. Accessed September 15, 2021.

Regulation (EU) 2017/625 of the European Parliament and of the Council of 15 March 2017 on official controls and other official activities performed to ensure the application of food and feed law, rules on animal health and welfare, plant health and plant protection products, amending Regulations (EC) No 999/2001, (EC) No 396/2005, (EC) No 1069/2009, (EC) No 1107/2009, (EU) No 1151/2012, (EU) No 652/2014, (EU) 2016/429 and 
(EU) 2016/2031 of the European Parliament and of the Council, Council Regulations (EC) No 1/2005 and (EC) No 1099/2009 and Council Directives 98/58/EC, 1999/74/EC, 2007/43/EC, 2008/119/EC and 2008/120/EC, and repealing Regulations (EC) No 854/2004 and (EC) No 882/2004 of the European Parliament and of the Council, Council Directives 89/608/EEC, 89/662/EEC, 90/425/EEC, 91/496/EEC, 96/23/EC, 96/93/EC and 97/78/EC and Council Decision 92/438/EEC (Official Controls Regulation). In: EUR-lex. Available at: https://eur-lex.europa.eu/. Accessed September 15, 2021

Romero MH, Uribe-Velásquez LF, Sánchez JA, Miranda-de la Lama GC 2013: Risk factors influencing bruising and high muscle $\mathrm{pH}$ in Colombian cattle carcasses due to transport and pre-slaughter operations. Meat Sci 95: 256-263

Schleicher C, Scheriau S, Kopacka I, Wanda S, Hofrichter J, Köfer J 2013: Analysis of the variation in meat inspection of pigs using variance partitioning. Prev Vet Med 111: 278-285

D'Souza N, Dunshea FR, Warner RD, Leury BJ 1998: The effect of handling pre-slaughter and carcass processing rate post-slaughter on pork quality. Meat Sci 50: 429-437

Troeger K, Meiler D 2007: Exsanguination of slaughter pigs - influence on meat quality. In Proceedings of the $53^{\text {rd }}$ International Congress of Meat Science and Technology, Beijing, China, pp. 603-604

Vecerek V, Voslarova E, Semerad Z, Passantino A 2020a: The health and welfare of pigs from the perspective of post mortem findings in slaughterhouses. Animals 10: 825

Vecerek V, Voslarova E, Semerad Z 2020b: Patho-anatomic findings in finisher pigs, sows, and piglets detected during veterinary slaughterhouse inspection. Acta Vet. Brno 89: 341-347

Valkova L, Vecerek V, Voslarova E, Kaluza M, Takacova D 2021: The welfare of cattle, sheep, goats and pigs from the perspective of traumatic injuries detected at slaughterhouse postmortem inspection. Animals 11: 1406 